\title{
Modelagem geoestatística de elementos maiores dos solos de Feira de Santana-Ba, Brasil
}

\section{Geostatistical modeling of larger elements of soils of Feira de Santana-Ba, Brazil}

Jonathas Jesus dos Santos, Programa de Pós-Graduação em Geografia Física, Universidade de São Paulo- USP, Brasil, jonathas@usp.br

(1) https://orcid.org/0000-0003-4558-7602

Washington de Jesus Sant'Anna da Franca Rocha, Instituto Nacional de Ciência e Tecnologia em Estudos Interdisciplinares e Transdisciplinares em Ecologia e Evolução (IN-TREE), Programa de PósGraduação Modelagem em Ciências da Terra e do Ambiente, Universidade Estadual de Feira de Santana, Brasil,wrocha@uefs.br

(1) https://orcid.org/0000-0002-2175-2792

Gustavo Macedo de Mello Baptista, Instituto de Geociências, Universidade de Brasília, Brasil, gmbaptista@unb.br

(1) https://orcid.org/0000-0002-1973-2725

Deorgia Tayane Mendes de Souza, Programa de Pós-Graduação Modelagem em Ciências da Terra e do Ambiente, Universidade Estadual de Feira de Santana, Brasil, deorgiasouza.geo@gmail.com

https://orcid.org/0000-0001-6791-3611

Ardemirio de Barros Silva, Programa de Pós-Graduação Modelagem em Ciências da Terra e do Ambiente, Universidade Estadual de Feira de Santana, Brasil, abarros@uefs.br

https://orcid.org/0000-0002-0892-0851

Sarah Moura Batista dos Santos, Departamento de Geografia, Universidade do Minho, Portugal, saamoura@gmail.com

(1D) https://orcid.org/0000-0001-5437-9202

Resumo: A variabilidade dos elementos do solo vem sendo estudada por técnicas de modelagem ambiental por meio da geoestatística. Essa pode ser uma ferramenta essencial para o desenvolvimento de projetos relacionados a métodos de interpolação e metodologias estatísticas para validar a correlação entre as características referentes aos solos. Nessa perspectiva, esse trabalho tem como objetivo modelar as características químicas naturais dos elementos maiores $\mathrm{P}, \mathrm{K}, \mathrm{Mg}, \mathrm{Ca}$, e $\mathrm{Na}$ dos solos de Feira de Santana-BA. Para tal, realizou-se a coleta das amostras de solos na área de estudo e foram realizadas as análises químicas em laboratório. Posteriormente foram removidos os outliers e efetuou-se a estatística descritiva dos atributos, avaliando também o coeficiente de correlação linear de Pearson entre os elementos. Calculou-se o tamanho do pixel, definiu-se o interpolador Krigagem por meio do cálculo dos resíduos e selecionou-se os critérios para classificação das propriedades. Os semivariogramas experimentais foram ajustados e em seguida produziu-se a Krigagem Ordinária, sendo também gerados mapas 2,5D. Observou-se que na maioria das vezes, as unidades de alta distribuição de elementos maiores estão ao oeste, em contrapartida, as áreas de baixa ao leste do município.

Palavras-chave: Química de solo; Variabilidade espacial; Distribuição de elementos.

Abstract: A variability of soil elements has been studied by environmental modeling techniques using geostatistics. This can be an essential tool for the development of projects related to interpolation methods and statistical methodologies to validate the correlation between soil characteristics. In this perspective, this work aims to model the natural chemical characteristics of the larger elements $P, K$, $\mathrm{Mg}, \mathrm{Ca}$ and $\mathrm{Na}$ of the soils of Feira de Santana-BA. To this end, it carried out a collection of solution samples in the study area and they were carried out as chemical analyzes in the laboratory. 
Subsequently, the outliers were removed and performed with a descriptive statistic of the attributes, also available or Pearson's linear correlation coefficient between the elements. Calculate the pixel size, define the Krigagem interpolator by calculating the residuals and select the standards for classifying properties. The experimental semivariograms were adjusted and followed produced in the Ordinary Krigagem, and 2.5D maps were also generated. It was observed that in most cases, the units of high distribution of larger elements are to the west, in contrast, the areas of low to the east of the municipality.

Keywords: Soil chemistry; Spatial variability; Distribution of elements.

\section{Introdução}

O conhecimento sobre a variabilidade dos atributos dos solos tornou-se uma questão estratégica, tanto do ponto de vista agrícola (com o objetivo de aumentar a eficiência e produtividade), quanto do ponto de vista ambiental (para avaliar os efeitos da antropização e da degradação do solo). Nessa perspectiva, a geoestatística tem desempenhado um papel fundamental na avaliação da variabilidade espacial de elementos nos solos (Ortiz, 2008; Silva, Lima, 2009; Manzione, Zimback, 2011; Zonta et al., 2014; Martins, Fernandes, 2017; Santos et al., 2019).

A avaliação da variabilidade pode ser uma ferramenta essencial para o desenvolvimento de projetos relacionados a métodos de interpolação e metodologias estatísticas para validar a correlação entre as características referentes aos solos (Ronquim, 2010). O emprego de técnicas de modelagem possibilita a criação de cenários, pelas simulações sobre um conjunto de equações que irão representar um processo (Martin et al., 2007). Para a modelagem de atributos do solo deve-se analisar as propriedades químicas, integrá-las e espacializá-las num Sistema de Informação Geográfica (SIG) (Bönisch, 2001; Ortiz, 2008).

As técnicas quantitativas de predição espacial por meio de modelagem em levantamentos de solos são comumente provenientes da geoestatística e de métodos estatísticos modernos por meio de estimativas espaciais para caracterização da variabilidade (Mcbratney et al., 2000; Bönisch et al., 2004). Um dos métodos geoestatísticos para esses estudos é a Krigagem que incorpora em seus ponderadores a dependência espacial entre as amostras. Esta dependência espacial é expressa por meio dos parâmetros do modelo de semivariograma ajustado (Almeida, 2013).

A geoestatística tem-se mostrado de grande utilidade, na ciência do solo, para caracterizar e mapear a variabilidade espacial de suas propriedades. Com ela podese fazer um levantamento completo do estado físico e químico da área, e caracterizar sua variabilidade espacial por meio de variogramas (Manzione, Zimback, 2011). Logo, este trabalho tem como objetivo modelar as características químicas naturais dos elementos maiores Fósforo $(P)$, Potássio $(K)$, Magnésio $(M g)$, Cálcio $(\mathrm{Ca})$, e Sódio (Na) dos solos de Feira de Santana-BA em um pixel de 332 metros. 


\section{1. Área de estudo}

A pesquisa foi realizada no município brasileiro de Feira de Santana, localizado no estado da Bahia, região nordeste do Brasil (Figura 1). Trata-se de um município comercial que está localizado no Agreste, área de transição biológica entre a Mata Atlântica e a Caatinga, com presença de fauna e flora dos dois ambientes (Dias \& Lobão, 2016). Está em uma área chamada "Polígono das Secas", com clima variando de seco a subúmido e prolongados períodos de estiagem (CPRM, 2005).

O município desempenha importante papel regional, servindo de ligação entre as regiões fisiográficas do litoral úmido e do interior semiárido, e entre as grandes regiões geográficas Nordeste e Sudeste do Brasil (Santo et al., 2013).
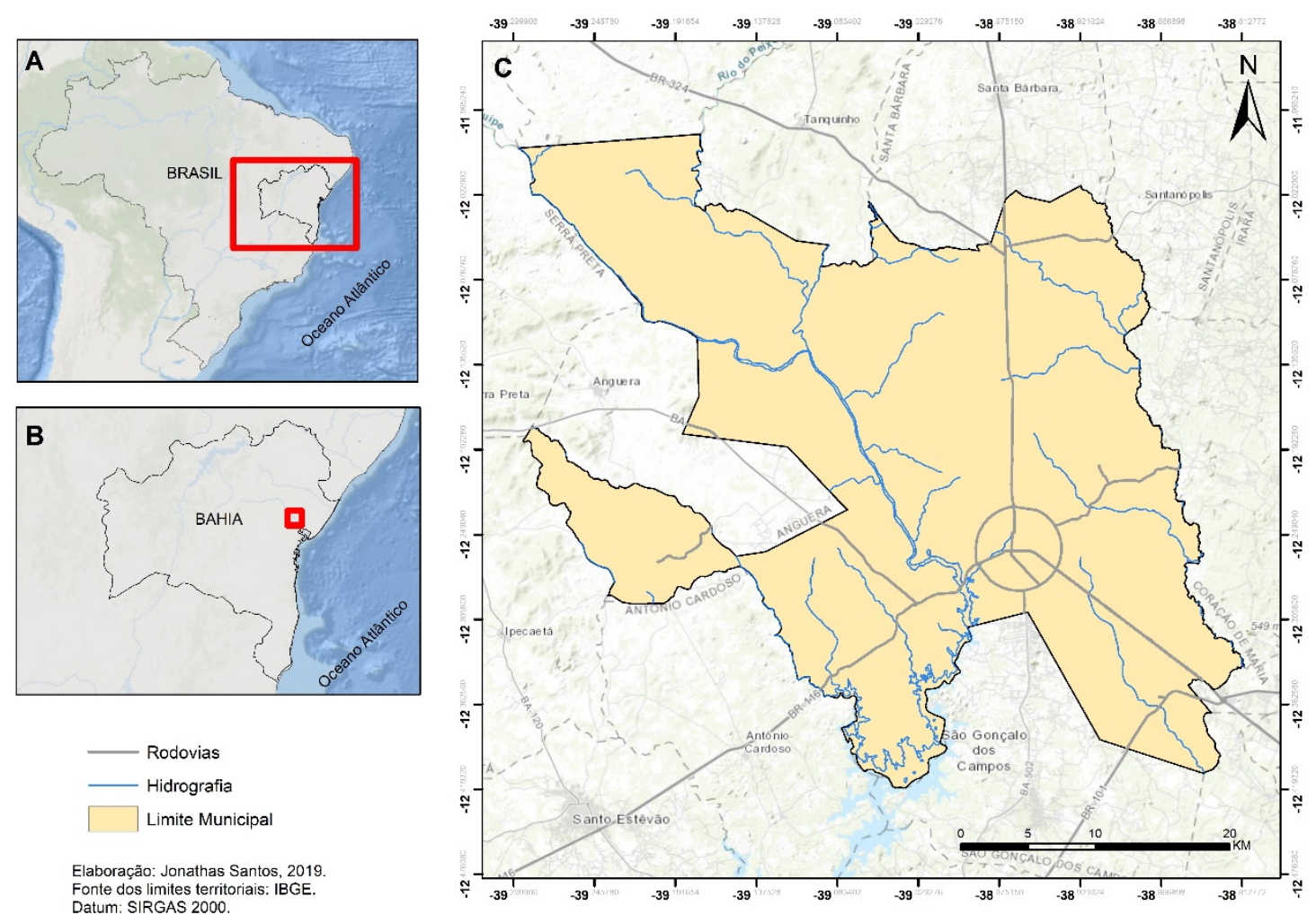

Elaboração: Jonathas Santos, 2019. Fonte dos limites territoriais: IBGE. Datum: SIRGAS 2000.

Figura 1: A - Localização do Estado da Bahia no Brasil. B - Localização do município de Feira de Santana no estado da Bahia. C - Limites territoriais do município de Feira de Santana.

De acordo com o IBGE (2018), predominam seis classes de solos (Figura 2). A leste, destaca-se os Argissolos Vermelhos-Amarelos e Argissolos Amarelos juntamente com uma faixa de Planossolos. Ao norte pequenas faixas de Latossolos. A oeste Planossolos, Neossolos Litólicos e Chernossolos.

O uso e ocupação da terra (Figura 3) é caracterizado em grande parte da área territorial pela agricultura e pecuária, o município também possui, lagos, açudes ou represas principalmente na porção leste. Na porção oeste observa-se a presença da vegetação caatinga, da floresta estacional e secundária. A vegetação natural do município é a caatinga arbórea e arbustiva, que se encontra bastante fragmentada 
nas partes mais baixas do relevo e bem preservada nas áreas de serras. $\mathrm{O}$ núcleo urbano está localizado na porção central do município (Dias, Lobão, 2016).
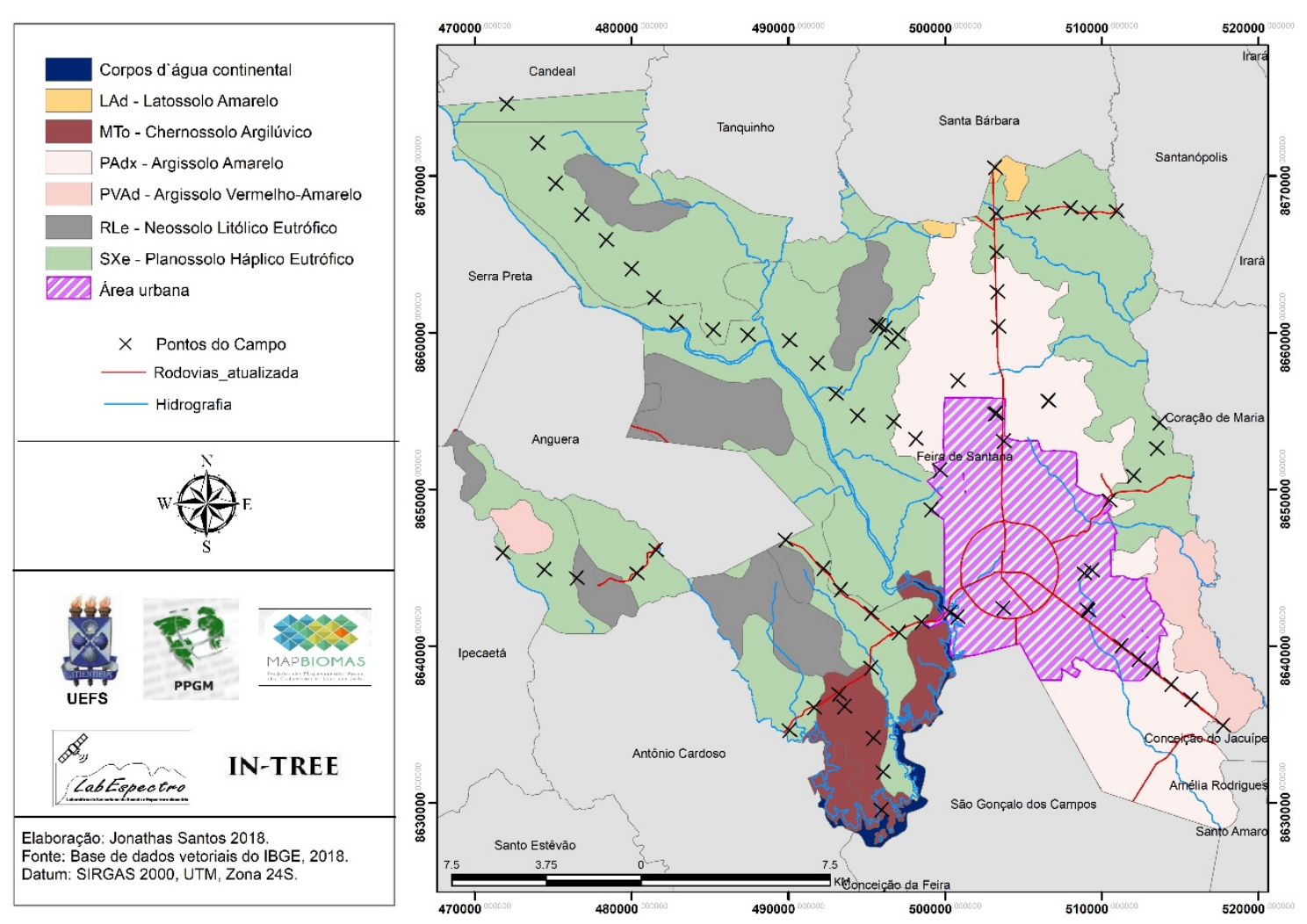

Figura 2: Pontos amostrais dos solos de Feira de Santana-BA.

Geomorfologicamente o município está localizado em uma área de Pediplano Sertanejo, na unidade geomorfológica dos Tabuleiros Interioranos, que são características de superfícies descontínuas modeladas e tabulares. Geologicamente, o município tem duas formações: o embasamento cristalino pré-cambriano, composto basicamente por granitos-gnaisses; e outra sedimentar de idade Pliocênica composta por conglomerados, areias e argila (Santos, Andrade, 2008). Nesse sentido, predomina a oeste do município o Gnaisse Granulítico e a leste rochas como Arenito, Arenito conglomegrado, Monzogranito, Quartzo, Sienogranito, Anfibolito e Migmatito. 

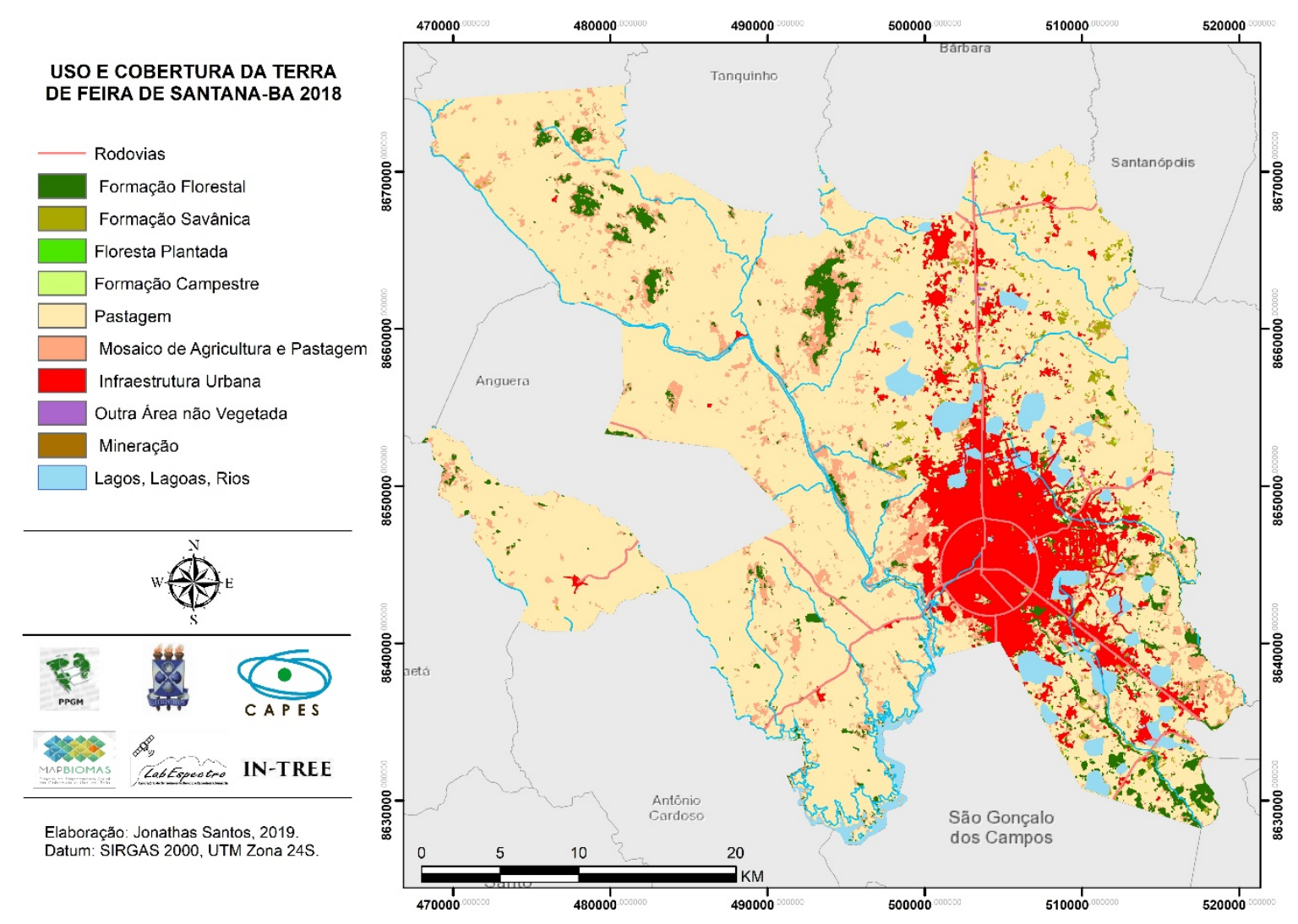

Figura 3: Classes do Mapbiomas do uso e cobertura da terra de Feira de Santana no ano de 2018.

\section{Materiais e Métodos}

\subsection{Coleta de amostras e configuração de dados}

Para a coleta de amostras foi utilizado o trado holandês em aço inox com perfuração de $25 \mathrm{~cm}$. Coletou-se amostras em várias partes do município e preferindo-se os lugares com menores intervenções humanas. A marcação dos pontos de coleta foi realizada com o GPS de modelo convencional de precisão de 4 metros. Foram coletados 74 pontos, com amostragem simples de uma amostra por ponto. Já distância média entre os pontos foi de 1500 metros. O padrão de distribuição de amostras escolhido foi de coletas nas quatro grandes regiões e nas principais classes de solos do município, incluindo coletas nos Latossolos Amarelos e Argissolos Vermelho-Amarelo (Figura 2). Posteriormente os pontos foram plotados no SIG.

Para o mapa de uso e cobertura da terra (Figura 3), utilizou-se os dados do Projeto de Mapeamento Anual da Cobertura e Uso do Solo do Brasil - MapBiomas. Trata-se de um projeto que têm desenvolvido uma série de metodologias para o monitoramento da dinâmica do uso e da cobertura da terra do Brasil, por meio das técnicas de sensoriamento remoto, com o uso plataforma de processamento digital em nuvem Google Earth Engine (Costa et al 2018). 


\subsection{Análise química de solos com verificação de outliers e estatística descritiva dos atributos}

Parte das amostras coletadas foram levadas para o laboratório de química de solo da Embrapa de Cruz das Almas-BA e a outra parte para o laboratório de química da Embrapa em Petrolina-PB. Foram realizadas análises químicas, sendo determinados a concentração total dos elementos maiores: $P, K, M g, C a$ e $\mathrm{Na}$. O método utilizado para a determinação do $P, K$, e Na foi com o extrator Mehlich 1 com determinação por absorção atômica. Já para a extração do $M g$ e Ca utilizou-se o $\mathrm{KCl} 1 \mathrm{M}$ também por absorção atômica (Embrapa, 2011).

Com os resultados da química de solo, observou-se a existência de outliers. Esses são valores extremos que se diferenciam dos outros por fugir da normalidade. Eles podem surgir por qualquer motivo, incluindo aqueles através de medições não laboratoriais e processos relacionados ao procedimento (Parrinello et al., 2016). Os outliers foram removidos utilizando o método de Chauvenet, que leva em consideração a média e o desvio padrão das amostras para a determinação dos valores aberrantes (Maples et al., 2018).

Em seguida, realizou-se um estudo exploratório nos resultados das análises, sendo determinadas as medidas de localização (mínimo, máximo, média, mediana e média geométrica), medidas de dispersão ou variabilidade (desvio padrão, coeficiente de variação, variação interquartil), e as medidas de assimetria e curtose. Tais análises permitiram a avaliação da normalidade dos atributos analisados de acordo com Carneiro et al. (2016).

As medidas de localização são informação sobre as correspondentes características populacionais ou parâmetros da população (Martins, 2015). É uma maneira de resumir ainda mais os dados apresentando um ou mais valores que sejam representativos para toda série (Morettin, Bussad, 2010). Como o exemplo das medidas de tendência central representada pela média, mediana e moda. Onde a média é a soma das observações divididas pelo número dela, a mediana a posição central da série e a mediana o valor que mais se repete (Morettin, Bussad, 2010).

As medidas de dispersão ou variabilidade são cálculos que podem resumir a informação contida na amostra, dando a designação da variabilidade ou dispersão da distribuição dos dados, ou seja, da maior ou menor dispersão dos dados relativamente a alguma medida de localização (Martins, 2015), a exemplo da variação interquartil é uma medida de variabilidade, com base na divisão de um conjunto de dados em quartis. Estes quartis dividem um rank ordena conjunto de dados em quatro partes iguais. O intervalo interquartil é igual a Q3 menos Q1 (Nanthakumar, Vijayalakshmi, 2016).

Também o Coeficiente de Variação (CV) que seria uma medida de dispersão criada para estimar a precisão de experimentos e representa o desvio-padrão expresso como porcentagem da média, quanto menor o CV maior homogeneidade entre os dados (Mohallem et al., 2008). O CV obtido pela razão entre desvio-padrão e a média dos 
dados, é uma importante ferramenta para análise da dispersão dos dados por ser uma medida relativa ao valor médio da série (Junior et al., 2010).

Já as medidas de assimetria e curtose é uma forma alternativa para verificar suposição de normalidade dos dados, refere-se à aplicação de testes baseados nos dois coeficientes (Santos, Ferreira, 2003).

\subsection{Cálculo do tamanho da célula e definição do interpolador}

O tamanho da grade ou pixel é uma etapa fundamental para a definição da resolução espacial em um mapa quando se leva em consideração o número de pontos amostrados (Silva, 2018). A equação para a cálculo da resolução espacial nesse caso, pode ser definida como:

\section{Equação 1:}

$$
\rho=0,0791 x \sqrt{\frac{A}{N}}
$$

Onde o $\rho$ seria o tamanho da célula (pixel), "0,0791" a regra geral do mapa recomendado para estudos de densidade de inspeção, "A" seria o tamanho da área em metros que está sendo estudada e o "N" o número das amostras que foram coletadas (Hengl, 2006). Nesse sentido, determinou-se o tamanho do pixel da área de estudo, levando em consideração o número de amostras coletadas e o tamanho da área.

De acordo com área de trabalho de 1.303.001.315 $\mathrm{m}^{2}$ e com 74 amostras coletadas foi definido pela Equação 1 um tamanho do pixel para a modelagem de elementos maiores de Feira de Santana de 332 metros.

Para a definição do interpolador, foi levando em consideração o cálculo dos resíduos. Essa é uma etapa importante já que o interpolador com uma menor quantidade de resíduos melhor representaria uma realidade espacial. Nessa perspectiva, avaliou-se o valor dos resíduos nos resultados das análises com os interpoladores Mínima Curvatura, o Inverso do Quadrado da Distância e a Krigagem ordinária. Para o cálculo dos resíduos utilizou-se o programa Surfer 9 e o Excel.

2.4. Ajuste dos semivariogramas experimentais para a modelação da área de estudo Os semivariogramas experimentais das propriedades químicas do solo foram ajustados sendo determinadas as estruturas de correlação da continuidade espacial.

Para o ajuste dos semivariogramas definiu-se os modelos, estabeleceu-se uma direção e a tolerância para cada atributo, sendo também observados o efeito pepita, contribuição e o alcance. Calculou-se os semivariogramas experimentais no programa geostatístico Surfer 9 por meio da Equação 2 (Journel, 1989): 


\section{Equação 2:}

$$
\gamma(h)=\frac{1}{2 N(h)} \sum_{i=1}^{N(h)}\left[Z\left(x_{i}\right)-Z\left(x_{i}+h\right)\right]^{2}
$$

Onde $\gamma(h)$ é o semivariograma estimado entre pares de pontos, $N(h)$ é o número de pares de valores medidos $Z\left(x_{i}\right)$ e $Z\left(x_{i}+h\right)$ medidos em locais afastados entre si da distância $h$, (Mello et al., 2003; Mello et al., 2005). Os parâmetros dos semivariogramas experimentais estão descritos na tabela IV. Optou-se por definir a direção omnidirecional para todas as variáveis em estudo, ou seja, não houve nenhuma direção preferencial de continuidade espacial.

2.5. Espacialização dos resultados por meio da Krigagem Ordinária e critérios para a classificação dos elementos maiores

A espacialização individual de cada uma das propriedades químicas avaliadas em laboratório foi realizada com o procedimento de interpolação geoestatística de Krigagem Ordinária (KO). Esse método observa a estimativa de uma variável em local não amostrado $\left(v^{*}\right)$ é obtida a partir da combinação linear dos $n$ dados amostrados $\left(v_{i}\right)$ disponíveis na vizinhança do ponto analisado, de acordo com a expressão geral (Bagnara et al., 2012):

\section{Equação 3:}

$$
v^{*}=\sum_{i=1}^{n} \lambda_{i} \cdot v_{i}
$$

Onde $\lambda_{i}(i=1,2, \ldots, n)$ são os pesos atribuídos a cada valor amostral, o $v_{i}$ são os dados experimentais e $n$ o número de elementos amostrais (Bagnara et al., 2012).

Os critérios utilizados para a classificação dos elementos maiores em unidades de modelos espaciais de baixa, média, média alta e alta foram os de Souza et al. (2015). Nesse sentido, observou-se os padrões utilizados para a classificação (Tabela I).

Tabela I: Padrões das propriedades dos elementos maiores

\begin{tabular}{ccccc}
\hline & Baixa & Média & Média-Alta & Alta \\
\hline$P\left(\mathrm{mg} / \mathrm{dm}^{3}\right)$ & 0 a 6 & 7 a 13 & 14 a 20 & $>20$ \\
\hline $\mathrm{K}\left(\mathrm{cmolC} / \mathrm{dm}^{3}\right)$ & 0 a 0,07 & 0,08 a 15 & 0,15 a 0,23 & $>0,23$ \\
\hline $\mathrm{Ca}\left(\mathrm{cmo} / \mathrm{C} / \mathrm{dm}^{3}\right)$ & 0 a 2,0 & 2,0 a 4,0 & - & $>4,0$ \\
\hline $\mathrm{Mg}\left(\mathrm{cmolC} / \mathrm{dm}^{3}\right)$ & 0 a 0,4 & 0,5 a 1,0 & - & $>1,0$ \\
\hline $\mathrm{Na}\left(\mathrm{cmolC} / \mathrm{dm}^{3}\right)$ & $<6$ & 6 a 15 & - & $>15$ \\
\hline \multicolumn{5}{c}{ Fonte: Souza et al. $(2015)$}
\end{tabular}




\section{Resultados e Discussão}

O interpolador que apresentou na generalidade menores resíduos foi a Krigagem, em comparação com Inverso do Quadrado da Distância (IQD) e a Mínima Curvatura (MIC) (Tabela II). Entretanto, no caso do $\mathrm{Mg}$ o interpolador que apresentou o menor valor de resíduos foi o MIC com 0.49 e para o $N a$ foi o IQD com um valor de 0.48 , valor aproximado da Krigagem com 0.49. Para o $P$ o melhor interpolador foi a Krigagem com um valor de -0.25 de resíduos, para o $K$ também a Krigagem com 0.26 , e no caso do Ca também a Krigagem com um valor de 0.44 .

Tabela II: Cálculo dos resíduos entre os interpoladores

\begin{tabular}{cccccc}
\hline & $\boldsymbol{P}$ & $\boldsymbol{K}$ & $\mathbf{C a}$ & $\mathbf{M g}$ & $\mathbf{N a}$ \\
\hline IQD $^{1}$ & -0.42995 & -0.62544 & 0.483928 & 0.910218 & 0.483632 \\
\hline MIC $^{2}$ & -0.44336 & -1.09715 & 0.665236 & 0.492241 & 0.549366 \\
\hline KRIG $^{3}$ & -0.25276 & 0.267033 & 0.449994 & 0.937942 & 0.493713 \\
\hline
\end{tabular}

${ }^{1}$ Inverso do Quadrado da Distância; ²Mínima Curvatura; 3Krigagem;

A estatística descritiva da química de solo (Tabela III) demonstra em primeiro lugar as medidas de localização, logo depois as de dispersão e as medidas de assimetria e curtose. O menor valor mínimo é o do $\mathrm{Na}$ com 0.03 e o maior o do $P$ com 414. A maior média também foi do $P$ com 55.4 e a menor do $\mathrm{Na}$ com 0.17 , bem como os valores de mediana 28.94 e 0.17 , respectivamente.

Tabela III: Estatística descritiva de elementos maiores dos solos de Feira de Santana-BA.

\begin{tabular}{|c|c|c|c|c|c|c|}
\hline & & $\begin{array}{c}\mathrm{Ca} \\
\left(\mathrm{cmolC}^{2}\right. \\
\left./ \mathrm{dm}^{3}\right)\end{array}$ & $\begin{array}{c}K \\
\left(\mathrm{cmolC}^{2}\right. \\
\left./ \mathrm{dm}^{3}\right)\end{array}$ & $\begin{array}{c}M g \\
\left(\mathrm{cmolC}^{2}\right. \\
\left./ \mathrm{dm}^{3}\right)\end{array}$ & $\begin{array}{c}\mathrm{Na} \\
\left(\mathrm{cmolC}^{2}\right. \\
\left./ \mathrm{dm}^{3}\right)\end{array}$ & $\underset{\substack{P \\
(\mathbf{m g} / \mathrm{dm}}}{P}$ \\
\hline \multirow{5}{*}{$\begin{array}{l}\text { Medidas de } \\
\text { localização }\end{array}$} & Mínimo & 0.38 & 0.05 & 0.18 & 0.03 & 0.71 \\
\hline & Máximo & 10.64 & 1.4 & 6.69 & 1.1 & 414 \\
\hline & Média & 3.79 & 0.31 & 1.81 & 0.27 & 55.4 \\
\hline & Mediana & 3.22 & 0.24 & 1.5 & 0.17 & 28.94 \\
\hline & $\begin{array}{c}\text { Média } \\
\text { Geométrica }\end{array}$ & 3.02 & 0.24 & 1.41 & 0.19 & 19.39 \\
\hline \multirow{3}{*}{$\begin{array}{l}\text { Medidas de } \\
\text { dispersão }\end{array}$} & $S D^{1}$ & 2.37 & 0.25 & 1.26 & 0.24 & 77.42 \\
\hline & $I Q R^{2}$ & 2.96 & 0.19 & 1.71 & 0.2 & 65 \\
\hline & $\mathrm{CV}^{3}$ & 0.62 & 0.81 & 0.69 & 0.91 & 1.39 \\
\hline \multirow{2}{*}{$\begin{array}{l}\text { Medidas de } \\
\text { Assimetria e } \\
\text { Curtose }\end{array}$} & $C s^{4}$ & 0.77 & 1.92 & 1.30 & 1.78 & 2.49 \\
\hline & $\mathrm{Ck}^{5}$ & 2.99 & 6.93 & 5.11 & 5.84 & 9.99 \\
\hline
\end{tabular}

${ }^{1}$ Desvio Padrão; ${ }^{2}$ Variação Interquartil; ${ }^{3}$ Coeficiente de Variação ${ }^{3}$; Coeficiente de Assimetria ${ }^{4}$ Coeficiente de Curtose ${ }^{5}$. Fonte: elaborada pelo autor 
Nesse sentido, o $P$ possui uma maior distribuição de valores e o $\mathrm{Na}$ uma menor distribuição em relação aos outros elementos. Esse fato também é verificado na mediana, onde o $P$ possui valor de 28.94 e o $N a$ 0.17, na média geométrica com valores de 19.39 e 0.19, respectivamente. O maior Desvio Padrão (SD) também é do $P$ com valor de 77.42 e os menores do $\mathrm{Na} 0.24$ e do $\mathrm{K} 0.25$.

O Intervalo Interquartil (IQR) revela que o maior valor foi do $P$ com 65 e o menor o $\mathrm{Na}$ com 0.2.0 menor Coeficiente de Variação (CV) foi a do Ca, com um valor de 0.62, já o maior CV foi a do $P$ com 1.39. Nesse sentido, é observável que o $P$ possui maior variabilidade no espaço analisado sendo o mais heterogêneo. Em contrapartida o $\mathrm{Ca}$ tem uma menor variabilidade apresentando uma maior homogeneidade entre os dados avaliados. Esse fato se deve a amostragem.

Os maiores valores do coeficiente de assimetria (Cs) também foi do $P$ com valor de 2.49 e o menor o do $C a$ com 0.77 . Os maiores valores de curtose (Ck) foi a do $P$ com 9.99 e a do K com 6.93, já os menores valores foram as do Ca e Mg com 2.99 e 5.11, respetivamente. Observa-se que os valores teóricos de Ck próximo de 3 indica a normalidade dos dados (Carvalho et al., 2002). Todos os semivariogramas experimentais foram ajustados como o modelo linear com um alcance de 21000 . $O$ maior efeito pepita foi o do $P$ e o menor o do $\mathrm{Na}$, a maior contribuição o do $\mathrm{Mg}$ e a menor do Na.

Tabela IV: Parâmetros dos modelos de semivariogramas experimentais

\begin{tabular}{cccccc} 
& Direção & Modelo & Efeito pepita & Contribuição & Alcance \\
\hline $\mathrm{Ca}\left(\mathrm{cmolc}_{\mathrm{c}} / \mathrm{dm}^{3}\right)$ & Omnidirecional & Linear & 0,12 & 0,22 & 21000 \\
\hline $\mathrm{K}\left(\mathrm{cmol} / \mathrm{dm}^{3}\right)$ & "' & "' & 0,06 & 0,10 & "' \\
\hline $\mathrm{Mg}\left(\mathrm{cmolc} / \mathrm{dm}^{3}\right)$ & "' & "' & 1,22 & 2,20 & "' \\
\hline $\mathrm{Na}\left(\mathrm{cmolc} / \mathrm{dm}^{3}\right)$ & "' & "' & 0,05 & 0,09 & "' \\
\hline $\mathrm{P}\left(\mathrm{mg} / \mathrm{dm}^{3}\right)$ & "' & "' & 41,22 & 0,90 & "' \\
\hline
\end{tabular}

Os semivariogramas experimentais podem ser observados na Figura 4. É verificável que o menor efeito pepita foi do $K$ com um valor de 0,6 e o maior a do $M g$ com 1,22. $\mathrm{O}$ alcance em todos os casos se aproximam de 21000. 

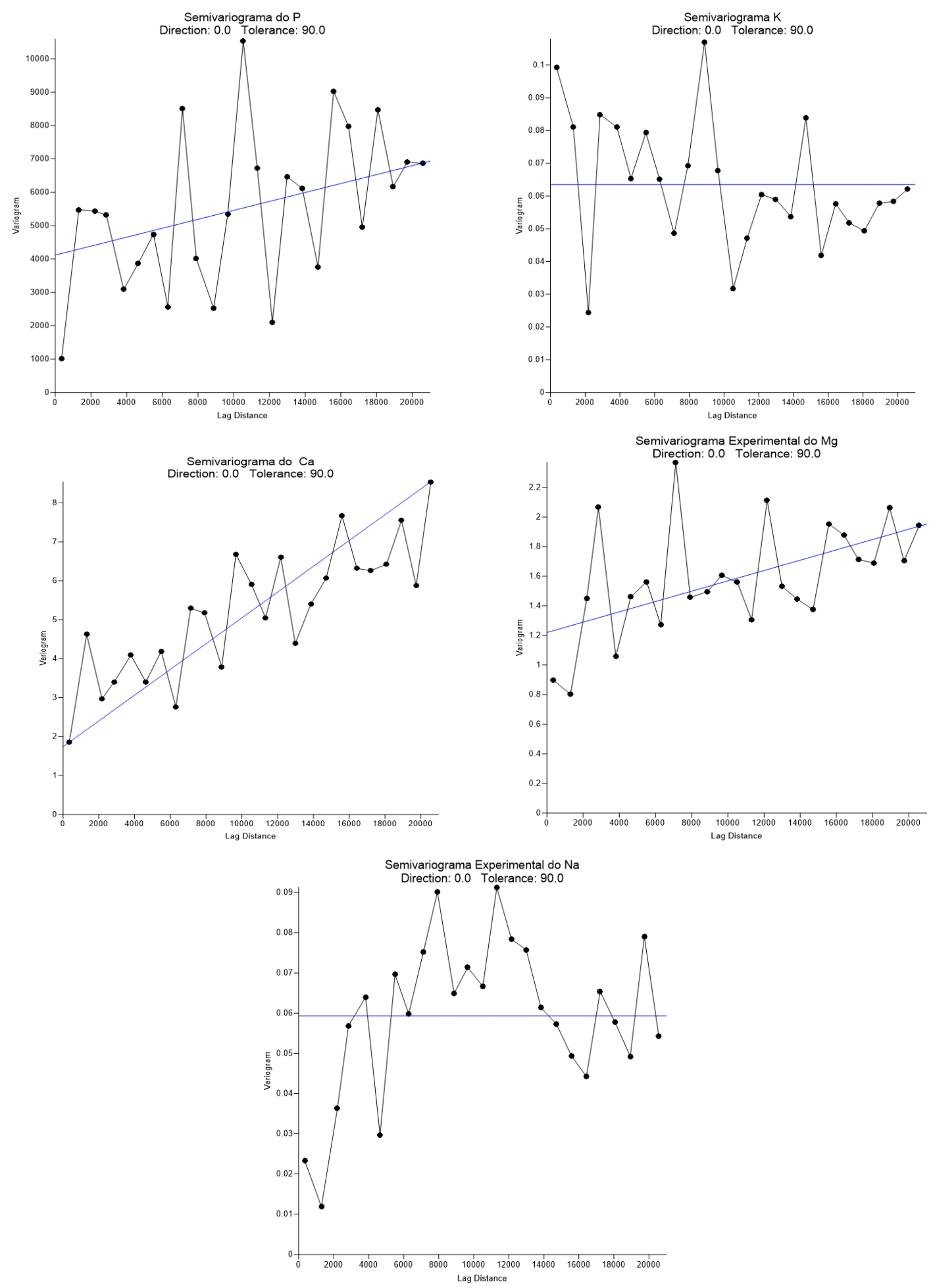

Figura 4: Semivariogramas experimentais dos elementos maiores dos solos de Feira de Santana-BA

O mapa da distribuição espacial do $P$ nos solos de Feira de Santana (Figura 5), revela uma baixa distribuição do elemento químico nos solos da porção leste e média em partes da porção oeste do município. As áreas de alta distribuição estão localizadas 
sobretudo na porção oeste, sudeste e norte do município. Tal fato fica evidenciado no modelo 2,5D (Figura 6).

$O P$ é um elemento necessário a qualquer forma de vida, ocorre em todos os ecossistemas. Entretanto, a quantidade de $P$ biodisponível presente no solo é muito variável e está dependente do equilíbrio que se estabelece entre o $P$ sorvido na fase sólida e o $P$ em solução na fase líquida do solo (Monteiro, Torrent, 2010). Nesse contexto, em solos jovens, os fosfatos de cálcio são os principais fornecedores de $P$ aos organismos vivos. Por outro lado, em solos altamente intemperizados, a biociclagem dos fosfatos orgânicos assume grande importância na manutenção da biodisponibilidade (Santos et al., 2008).

Nesse sentido, constata-se com a observação do mapa de uso e cobertura da terra (Figura 3) que a agricultura e pastagem são as classes predominantes na porção oeste, sul e norte da cidade. Logo, um alto valor de $P$ nos solos da porção oeste do município pode ser essencial para o fornecimento de nutrientes para a vegetação $e$ consequentemente para o sistema agropecuário da cidade. Em contrapartida, as unidades de baixa distribuição de $P$ estão localizadas principalmente em áreas de expansão da mancha urbana do município, que estão localizadas na porção leste.

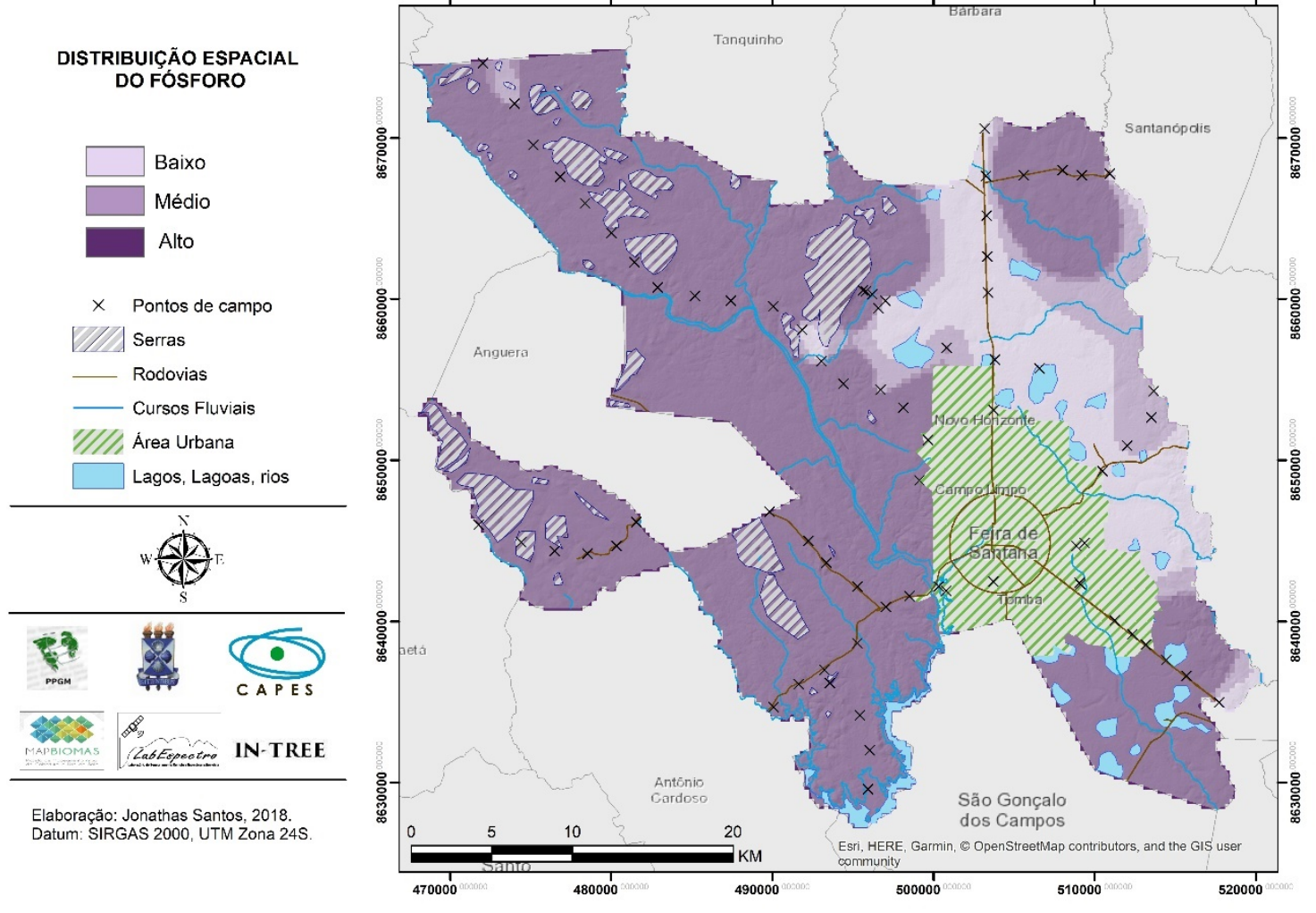

Figura 5: Modelo de distribuição espacial da concentração de $P$ em $m g / d m^{3}$ 


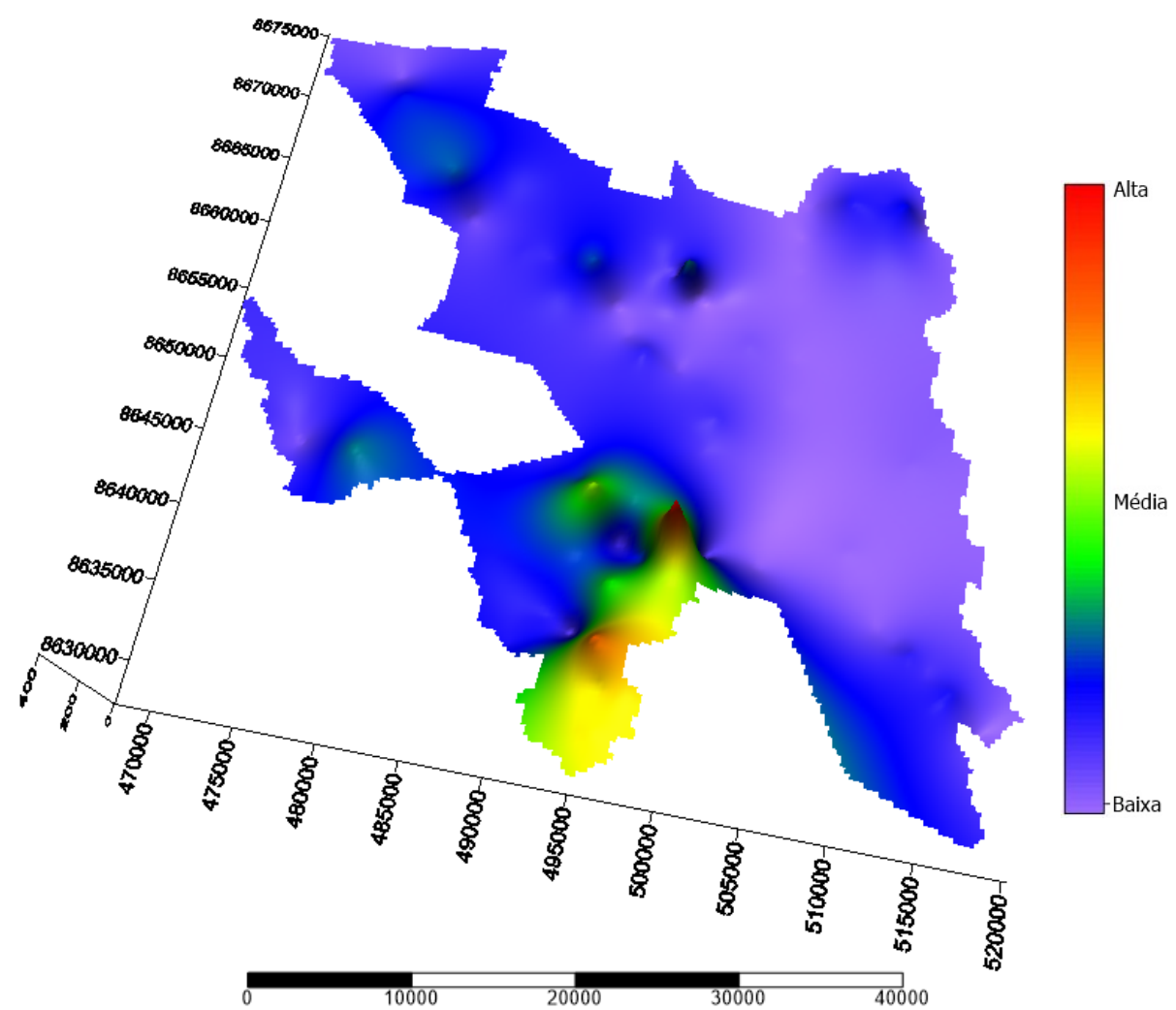

Figura 6: Modelo 2,5D da distribuição espacial do $P$ em Feira de Santana-BA

A distribuição espacial do $K$ (Figura 7), revela que a maior quantidade do elemento químico está distribuída na porção norte, oeste e sudoeste do município. As áreas com valores mais baixos de distribuição estão concentradas sobretudo na porção leste e em algumas áreas do sudeste. Já as áreas de média e média-alta distribuição estão localizadas principalmente a leste do município e algumas áreas do sudoeste. Tal fato, também pode ser verificado no mapa 2,5D de distribuição do $K$ (Figura 8).

$O K$ é o segundo nutriente mineral requerido em maior quantidade pelas espécies vegetais, depois do nitrogênio (Rosolem et al., 2006). É possível que a disponibilidade desse elemento químico esteja mais intimamente relacionada com a composição mineralógica do solo (Melo et al., 2004). Diante disso, o uso e cobertura da terra (Figura 3) nas unidades de média a alta distribuição, em sua maior parte, também está caracterizada pela agricultura e pastagem, assim como as unidades de baixa distribuição espacial, porém em uma menor quantidade.

Nesse sentido, um alto valor de $K$ também poderia beneficiar o sistema agropecuário dessa região, visto que se trata de um nutriente mineral que pode beneficiar a vegetação. As áreas de maiores benefícios estão ao oeste, sobretudo ao norte, noroeste e sudoeste do município de Feira de Santana. 

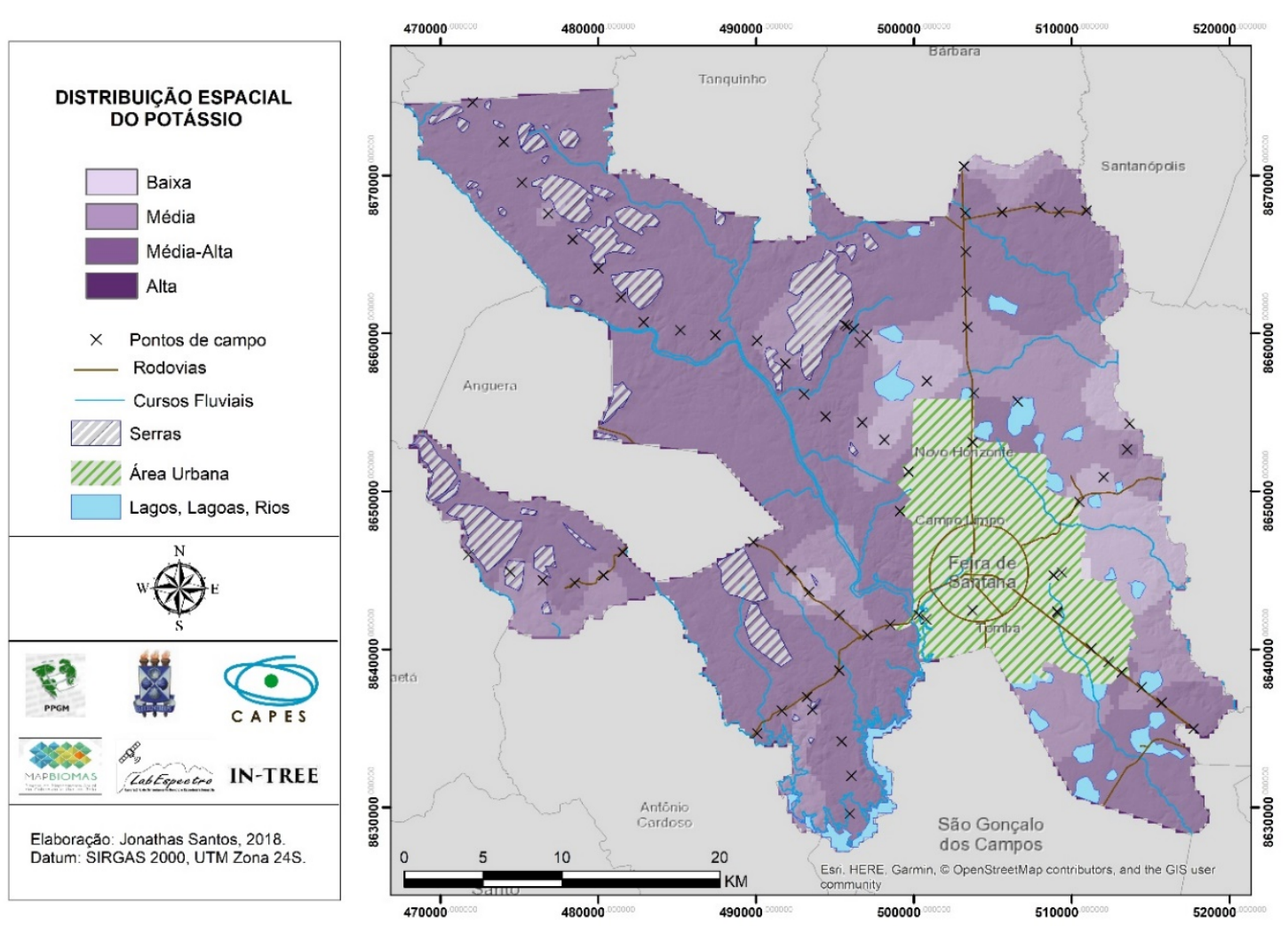

Figura 7: Modelo de distribuição espacial do $\mathrm{Kem} \mathrm{cmo} / \mathrm{C} / \mathrm{dm}^{3}$

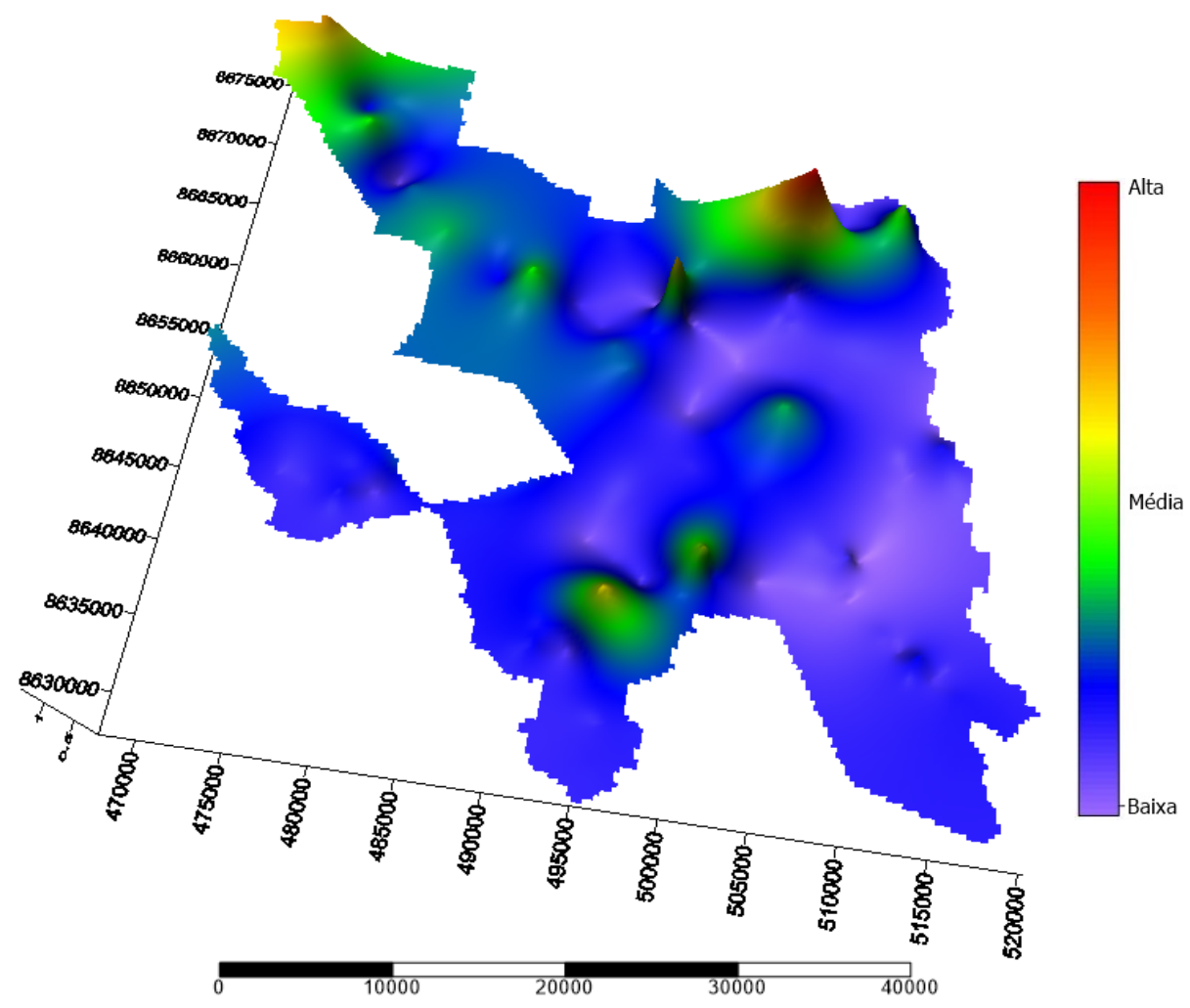

Figura 8: Modelo 2,5D do K em Feira de Santana-Ba

O Ca está distribuído nos solos de Feira de Santana em um padrão de baixa concentração na porção leste em contraposição a porção oeste (Figura 9), fato 
também verificado no modelo 2,5D (Figura 10). As áreas com concentração baixa estendem-se sobretudo na porção leste do município, as de média estão localizados principalmente na porção oeste com concentrações também no sudeste e norte, já as áreas de alta concentração estão ao oeste do município, sobretudo na porção sudoeste.

O Ca é nutriente essencial para o crescimento das plantas, a sua falta no solo aliada a outros fatores como o aumento da acidez e excesso de alumínio tem como consequência um franco crescimento do sistema radicular das espécies vegetais, o que pode acarretar em uma baixa captação de nutrientes (Maria et al., 1993). Dessa forma, identifica-se que o uso e ocupação da terra (Figura 3 ) nas unidades de alta distribuição espacial do $\mathrm{Ca}$ na maioria das vezes é caracterizada também pela pastagem e agricultura. As unidades de média distribuição pela agricultura, pastagem e áreas de expansão urbana, caso identificado na porção sudeste do município.

Já as unidades de baixa distribuição estão concentradas em áreas de pastagem, agricultura e expansão da mancha urbana. Nesse sentido, o Ca também poderia beneficiar o sistema agropecuário do município, já que se trata de um nutriente para vegetação. As áreas de maiores benefícios estariam na porção oeste do município, sobretudo na porção sudoeste.
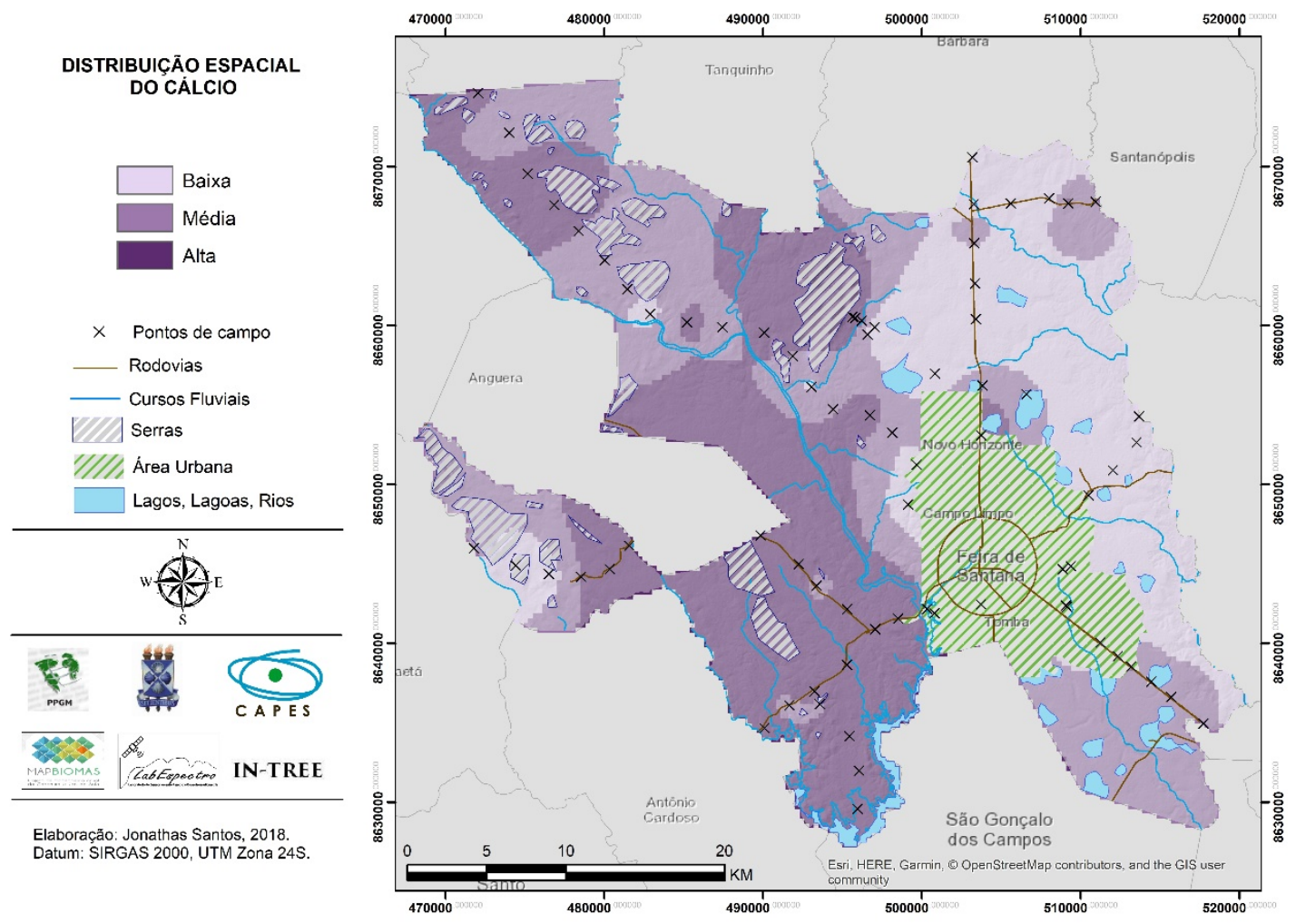

Figura 9: Modelo de distribuição espacial do $\mathrm{Ca}$ em $\mathrm{cmol} / \mathrm{dm} \mathrm{m}^{3}$ 


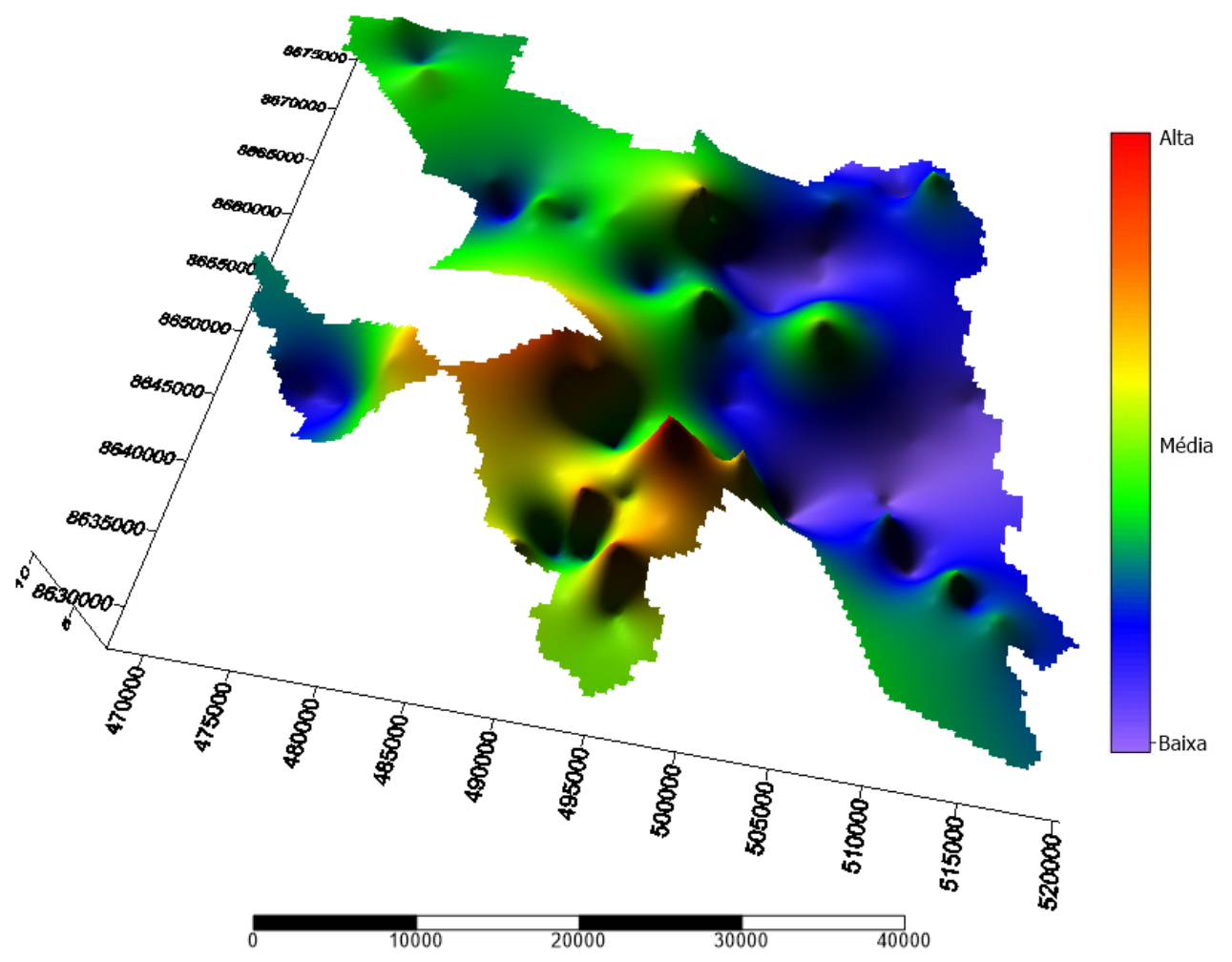

Figura 10: Modelo 2,5D do Ca em Feira de Santana-BA

O Mg possui diferentes padrões de distribuição no município (Figura 11), fato também verificado no modelo 2,5D (Figura 12). Apresenta uma distribuição sobretudo média na porção leste e em uma pequena parte norte do município. Já as áreas de alta concentração estão localizadas praticamente em todas as quatro grandes regiões com menos intensidade na porção leste.

Nessa perspectiva, o $M g$ é um dos macronutrientes essenciais para as espécies vegetais (Benites et al., 2009). O material de origem do solo e a sua taxa de intemperismo são certamente os condicionadores do estado do magnésio nos solos, mas existem outros fatores que colaboram o balanço do $\mathrm{Mg}$, como as entradas através de precipitação e fertilização e as saídas através da exportação das culturas, podas, lixiviação e erosão (Portela, Pires, 1995).

Logo, observando o mapa de uso e cobertura da terra (Figura 3), verifica-se que a classe de pastagem e agricultura, também, ocupam a maior parte das unidades de média e alta distribuição espacial do $M g$. Em contrapartida, a área de baixa distribuição está em uma área de expansão urbana a leste do município. Logo, um alto valor de $M g$ também pode ser fundamental para a agropecuária. As áreas de maiores benefícios estão ao leste e norte do município. 

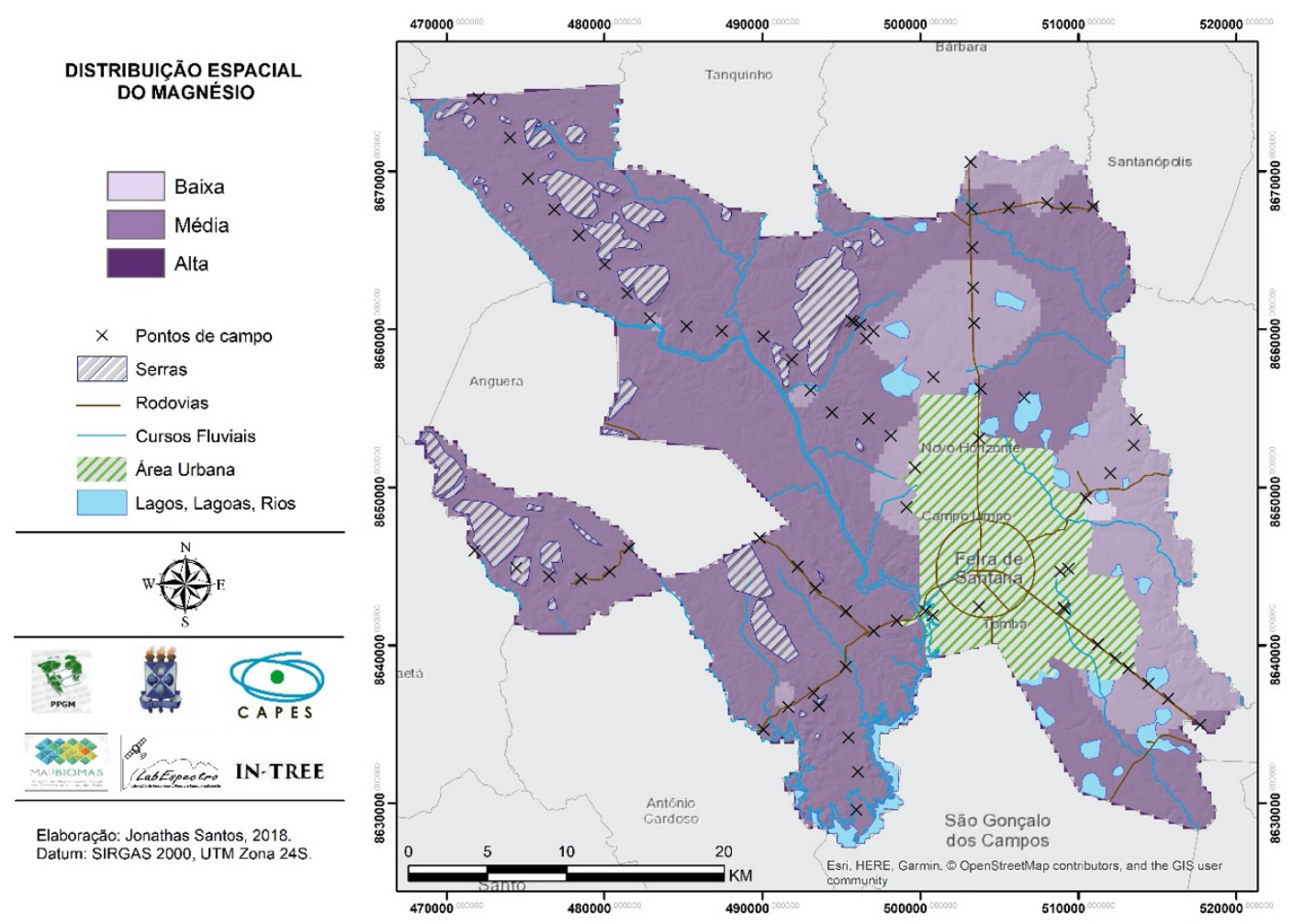

Figura 11: Modelo de distribuição espacial do $\mathrm{Mg}$ em $\mathrm{cmo} / \mathrm{C} / \mathrm{dm}^{3}$

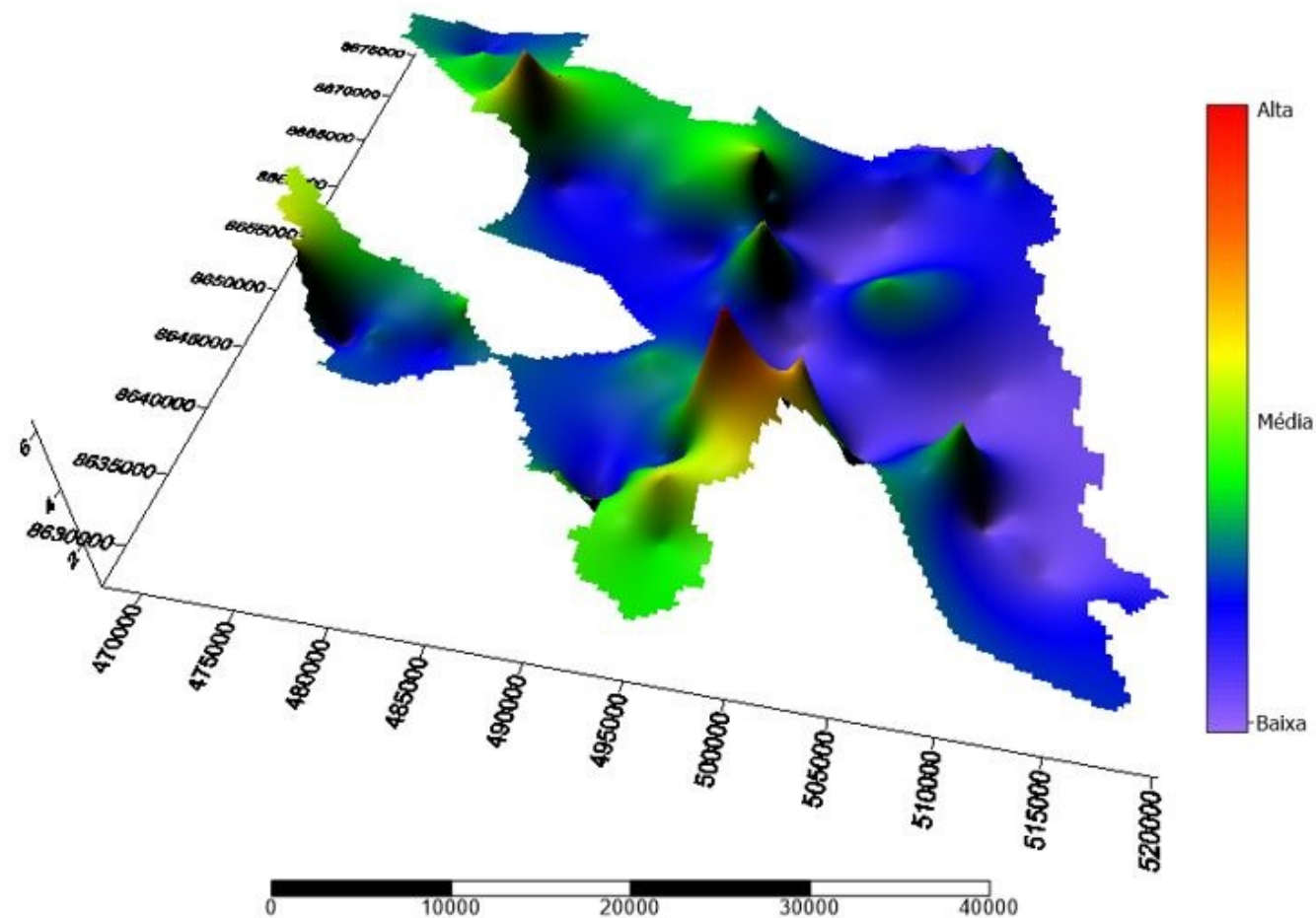

Figura 12: Modelo 2,5D do Mg em Feira de Santana-BA

O Sódio $(\mathrm{Na})$ possui sobretudo uma baixa distribuição nos solos de Feira de Santana em todas as quatro regiões (Figuras 13 e 14). As áreas de média distribuição estão localizadas a noroeste do município e em uma pequena parte do leste e sudoeste. Em 
contrapartida, as áreas de alta concentração de sódio não foram registradas dentro dos parâmetros da Embrapa para alta concentração.
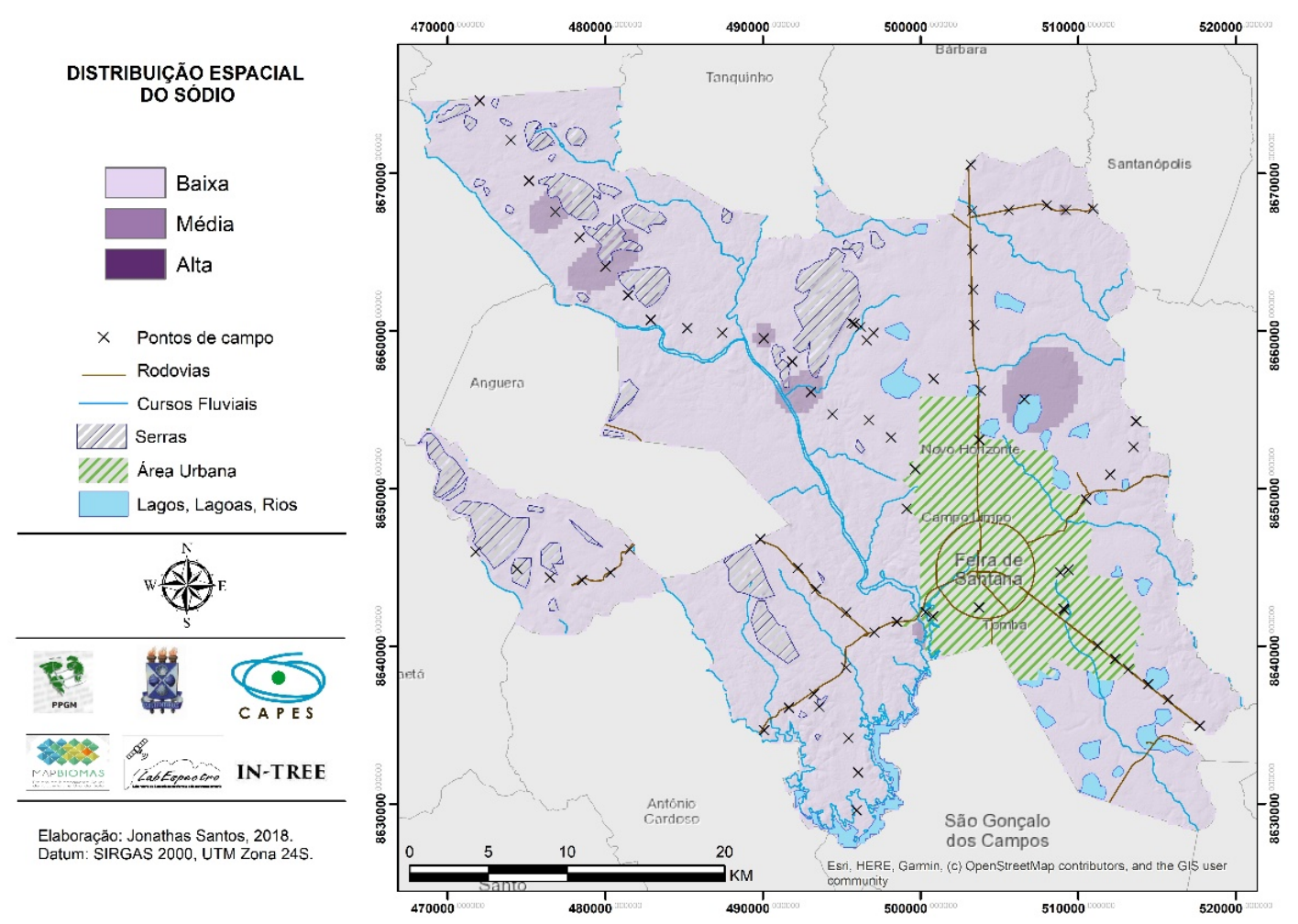

Figura 13: Modelo de distribuição do $\mathrm{Na}$ em $\mathrm{cmol} / \mathrm{dm}^{3}$

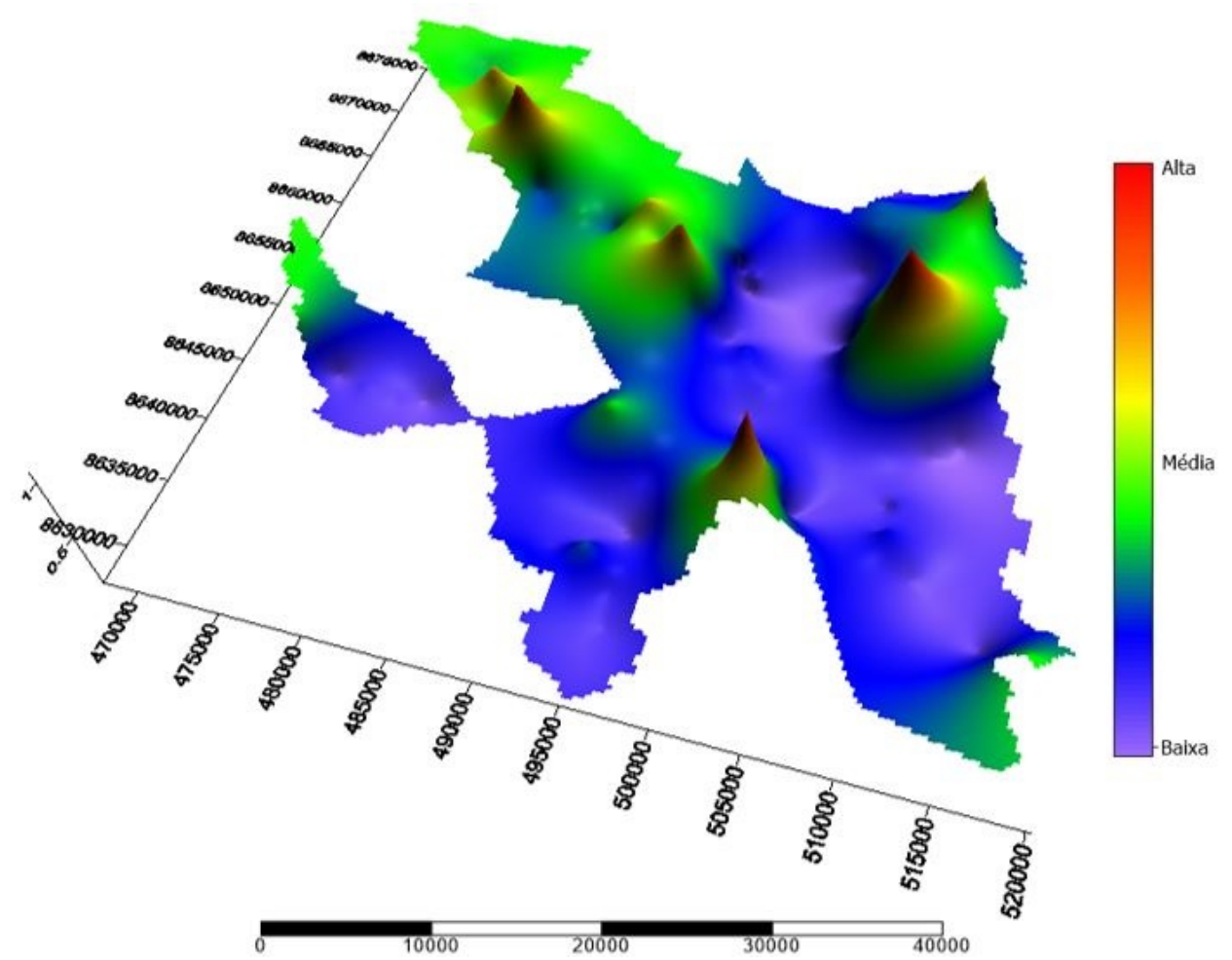

Figura 14: Modelo 2,5D do Na em Feira de Santana 
O excesso de Na pode causar o processo de salinização dos solos e limitar o rendimento das culturas (Lima et al., 2008). Entretanto, sabe-se que o $\mathrm{Na}$, têm presença em solos e águas e são amplamente absorvidos e utilizados pelas plantas, mas não são considerados como nutrientes para as plantas porque não atendem à definição estrita de "essencialidade" (Subbarao et al., 2003).

Neste caso, é verificado que nas unidades de baixa distribuição espacial do $\mathrm{Na}^{+}$está concentrado nas classes de agricultura e pastagem, assim como os de média distribuição (Figura 3). A baixa distribuição de $\mathrm{Na}^{+}$pode beneficiar o sistema agropecuário do município, tendo em vista que a alta concentração deste elemento é prejudicial para a vegetação.

\section{Conclusões}

A modelagem geoestatística dos elementos maiores dos solos de Feira de Santana$\mathrm{Ba}$, em um pixel de 332 metros, revelou que a região possui diferentes padrões espaciais de distribuição dos elementos maiores analisados. Entretanto, em todos os casos, observou-se que na maioria das vezes, as unidades de grande concentração de elementos maiores estão ao oeste do município, tratando-se de uma área com maior predominância da agricultura e pastagem.

Por outro lado, a porção leste que é caracterizada pela expansão da mancha urbana e pela agricultura e pastagem, apresentou em grande parte dos resultados uma baixa distribuição espacial de elementos maiores. Tal fato pode evidenciar interferências antrópicas no uso e cobertura do solo. Também uma área de transição, visto que o município se encontra no agreste, que é uma área transicional entre a Mata Atlântica e a Caatinga.

As altas ocorrências de elementos maiores nos solos do oeste do município podem ser fundamentais para as práticas agrícolas na região. Entretanto, para uma melhor resolução espacial e uma maior representatividade da variabilidade dos elementos maiores nos solos seria necessário um maior número de amostras, tendo em vista o tamanho do município que possui uma grande área territorial e o número de amostras coletadas neste estudo.

\section{Agradecimentos}

Ao Programa de Pós-Graduação Modelagem em ciências da Terra e do Ambiente (PPGM), da Universidade Estadual de Feira de Santana (UEFS). Ao Instituto Nacional em Ciência e Tecnologia em Estudos Interdisciplinares e Transdisciplinares em Ecologia e Evolução (INCT IN-TREE). Ao Projeto de Mapeamento Anual da Cobertura e Uso do Solo no Brasil (MapBiomas). A Coordenação de Aperfeiçoamento de Pessoal de Nível Superior (CAPES), número do processo 1700972.

\section{Financiamento}


Este trabalho recebeu apoio financeiro da Coordenação de Aperfeiçoamento de Pessoal de Nível Superior (CAPES), número do processo 1700972.

\section{Bibliografia}

Almeida, M. F. F. (2013). Uso da Krigagem indicativa na seleção de áreas propícias ao cultivo do café em consorciação ou rotação com outras culturas. Viçosa: UFV.

Bagnara, D., Prietto, P. D. M., Timbola, R. S. (2012). Aplicação da krigagem ordinária na modelagem do $\mathrm{pH}$ e da dureza da água subterrânea na área central de Passo Fundo - RS.

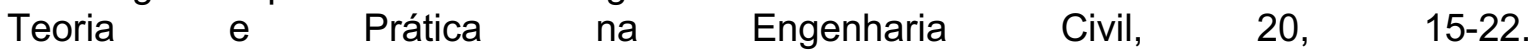
http://www.editoradunas.com.br/revistatpec/Art2 N20.pdf

Benites, V. M., Carvalho, M. C. S., Resende, A. V., Polidoro, J. C., Bernardi, A. C. C., Oliveira, F. A. (2010). Potássio Cálcio Magnésio na Agricultura Brasileira. In: Prochnow, L.I; Casarin, V.; Stipp, S.R. (Org.). Boas Práticas para Uso Eficiente de Fertilizantes. Piracicaba: IPNI, 2, 53-65.

Bönisch, S. (2001). Geoprocessamento ambiental com tratamento de incerteza: o caso do zoneamento pedoclimático para a soja no Estado de Santa Catarina. Dissertação Mestrado, Instituto Nacional de Pesquisas Espaciais, São José dos Campos.

Bönisch, S., Assad, M. L. L., Monteiro, A. M. V., Câmara, G. (2004). Representação e propagação de incertezas em dados de solo. II - Atributos numéricos. R. Bras. Ci. Solo, 28, 33-47. https://doi.org/10.1590/S0100-06832004000100003

Carneiro, J. S. S., Faria, A. J. G., Fidelis, R. R., Neto, S. P. S., Santos, A. C., Silva, R. R. (2016). Diagnóstico da Variabilidade Espacial e Manejo da Fertilidade do Solo no Cerrado. Curitiba: R. Scientia Agraria, 17(3), 38-49. http://dx.doi.org/10.5380/rsa.v17i3.50096

Carvalho, J. R. P., Silveira, P. M., Vieira, S. R. (2002). Geoestatística na determinação da variabilidade espacial de características químicas do solo sob diferentes preparos. Pesq. agropec. bras., Brasília, 37(8),1151-1159. https://doi.org/10.1590/S0100$\underline{204 X 2002000800013}$

CPRM (2005). Projeto Cadastro de Fontes de Abastecimento por Água Subterrânea Diagnóstico do Município de Feira de Santana - Bahia / Organizado [por] Vieira. A, Melo F., Lopes, H.B.V; Campos, J.C.V.; Guimarães J.T., Bomfim, L.F.C.; Couto, P.A.A.; Benvenuti, S.M.P. Salvador: CPRM/PRODEEM.

Costa, D. P., Santos, J. J., Chaves, J. M., Rocha, W. J. S. F., Vasconcelos, R. N. (2018). Novas Tecnologias e Sensoriamento Remoto: Aplicação de uma oficina didática para a disseminação das potencialidades dos produtos e ferramentas do MapBiomas. Sustainability, Agri, Food and Environmental Research., 6(3), 36-46. http://dx.doi.org/10.7770/safer-V0N0-art1402

Dias, L. F., Lobão, J. S. B. (2016). Um olhar sobre o município de Feira de Santana: a Geografia e o Geoprocessamento num contexto socioambiental. Feira de Santana: UEFS Editora.

Embrapa. (2011) Manual de métodos de análise de solos. Rio de Janeiro: Embrapa Solos.

Hengl, T. (2006). Finding the right pixel size. Computers \& Geosciences, 32(9), 1283-1298. https://doi.org/10.1016/j.cageo.2005.11.008

IBGE. Geociências (2018). Informações ambientais, Pedologia, Escala 250 mil. Disponível em: https://downloads.ibge.gov.br/downloads geociencias.htm

Journel, A. G. (1989). Fundamentals of geostatistics in five lessons. Washington, American Geophysical Union. 
Junior, J. C. O., Souza, L. C. P., Melo, V. F. (2010). Variabilidade de Atributos Físicos e Químicos de Solos da Formação Guabirotuba em diferentes Unidades de Amostragem. R. Bras. Ci. Solo, 34(5), 1491-1502. https://doi.org/10.1590/S0100-06832010000500002

Lima, F. S., Barros, M. F. C., Ferraz, F. B., Junior, S. S., Oliveira, L. B. (2008). Absorção de Nutrientes e Sódio pelo Caupi em Solos Salino-Sódicos Corrigidos com Gesso. Revista Caatinga, $21(5)$,

95-101. https://periodicos.ufersa.edu.br/index.php/caatinga/article/view/179/489

Lira, S. A., Neto, A. C. (2006). Coeficientes de correlação para variáveis ordinárias e dicotômicas derivados do coeficiente linear de Pearson. RECIE: Uberlândia, 15(1/2), 4553. http://www.seer.ufu.br/index.php/cieng/article/view/529/489

Maples, M. P., Reichart, D. E., Berger, T. A., Trotter, A. S., Martin, J. R., Paggen, M. L., Joyner, R. E., Salemi, C. P., Dutton, D. A. (2018). Robust Chauvenet Outlier Rejection. Astrophysical Journal Supplement Series, 238(1), 2. https://doi.org/10.3847/15384365/aad23d

Maria, I. C., Rosserto, R., Ambrosano, E. J., Castro, O. M. (1993). Efeito da adição de diferentes fontes de Cálcio no movimento de cátions em colunas de solos. Piracicaba: Sci. Agric., 50, 87-98. https://doi.org/10.1590/S0103-90161993000100013

Martins, E. G. M., (2015). Medidas de localização, Rev. Ciência Elem., 3(2), 125.

Martins, E. G. M., (2015). Medidas de dispersão, Rev. Ciência Elem., 3(2), 126.

Martins, J. C., Fernandes, R. (2017). Processos de degradação do solo - medidas de prevenção. Dossier Técnico Vida Rural.

Martin, T. N., Storck, L., Neto, D. D. (2007). Simulação estocástica da radiação fotossinteticamente ativa e da temperatura do ar por diferentes métodos. Brasília, Pesq. agropec. bras., 42(9), 1211-1219. https://doi.org/10.1590/S0100-204X2007000900001

Manzione, R. L., Zimback, C. R. L. (2011). Análise espacial multivariada aplicada a avaliação da fertilidade do solo. Viçosa-MG: Eng. na Agricul. REVENG, 19(3), 227-235. https://doi.org/10.13083/reveng.v19i3.181

Mcbratney, A. B., Odeh, I. O. A., Bishop, T. F. A., Dunbar, M. S., Shatar, T. M. (2000). An overview of pedometric techniques for use in soil survey. Geoderna, 97(3-4), 293-327. https://doi.org/10.1016/S0016-7061(00)00043-4

Melo, G. W., Meurer, E. J., Pinto, L. F. S. (2004). Fontes de Potássio em Solos Distroférricos Cauliníticos Originados De Basalto No Rio Grande Do Sul. R. Bras. Ci. Solo, 28(4), 597603. http://dx.doi.org/10.1590/S0100-06832004000400002

Mello, C. R., Lima, J. M., Silva, A. M., Mello, J. M., Oliveira, M. S. (2003) Krigagem e o inverso do quadrado da distância para interpolação dos parâmetros da equação de chuvas intensas. R. Bras. Ci. Solo, 27(5), 925-933. http://dx.doi.org/10.1590/S010006832003000500017

Mello, J. M., Batista, J. L. F., Júnior, P. J. R., Oliveira, M. S. (2005). Adjustment and selection of spatial models of semivariogram envisaging Eucalyptus grandis volumetric estimates. Scientia Forestales, 69, 25-37. https://www.ipef.br/publicacoes/scientia/nr69/cap02.pdf

Mohallem, D. F., Tavares, M., Silva, P. L., Guimarães, E. C., Freitas, R. F. (2008). Avaliação do coeficiente de variação como medida da precisão em experimentos com frangos de corte. Arq. Bras. Med. Vet. Zootec., 60(2), 449-453. http://dx.doi.org/10.1590/S010209352008000200026

Monteiro, M. C. H., Torrent, J. (2010). Dinâmica do fósforo no solo: perspectiva agronómica e ambiental. Castelo Branco: IPCB.

Morettin, P. A.; Bussab, W. O. (2010). Estatística básica. São Paulo: Saraiva, 6. ed. 540 p. 
Nanthakumar, C., Vijayalakshmi, S. (2016). Construction Of Inter Quartile Range (IQR) Control Chart Using Process Capability For Mean Using Range. International Journal of Science, Engineering and Technology Research (IJSETR), 5(1), 114-118. http://ijsetr.org/wpcontent/uploads/2016/01/IJSETR-VOL-5-ISSUE-1-114-118.pdf

Ortiz, J. O. (2008). Análise de Risco na fase de Planejamento em Sistemas de Produção Agrícola por meio da Simulação Geoestatística Condicionada. São José dos Campos-SP: INPE, Brasil.

Parrinello, C. M., Grams, M. E., Sang, Y., Couper, D., Wruck, L. M., Li, D., Eckfeldt, J. H., Selvin, E., Coresh, J. (2016). Iterative Outlier Removal: A Method for Identifying Outliers in Laboratory Recalibration Studies. Clinical Chemistry, 62(7), 966-972. https://doi.org/10.1373/clinchem.2016.255216

Portela, E., Pires, A. L. (1995). Nutrient deposition and leaching by rainwater in low and intensively managed chestnut groves. Proceedings Conference on Erosion and Land Degradation in Mediterranean, Universidade de Aveiro, Portugal. 307-317.

Ronquim, C. C. (2010). Conceitos de fertilidade do solo e manejo adequado para as regiões tropicais. Campinas: Embrapa.

Rosolem, C. A., Santos, F. P., Foloni, J. S. S., Calonego, J. C. (2006). Potássio no solo em consequência da adubação sobre a palha de milheto e chuva simulada. Brasília: Pesq. agropec. bras.,41(6), 1033-1040. http://dx.doi.org/10.1590/S0100-204X2006000600020

Santos, A. C., Ferreira, D. F. (2003). Definição do tamanho amostral usando simulação Monte Carlo para o teste de normalidade baseado em assimetria e curtose. I. Abordagem univariada. Lavras: Ciênc. agrotec., 27(2), 432-437. http://dx.doi.org/10.1590/S1413$\underline{70542003000200025}$

Santos, D. R., Gatiboni, L. C., Kaminski, J. (2008). Fatores que afetam a disponibilidade do fósforo e o manejo da adubação fosfatada em solos sob sistema plantio direto. Santa Maria: Ciência Rural, 38(2), 576-586. http://dx.doi.org/10.1590/S0103-84782008000200049

Santos, J. J., Franca-Rocha, W. J. S., Baptista, G. M. M., Souza, D. T. M., Silva, A. B., Santos, S. M. B. (2019). Análise Bibliométrica da Espectrorradiometria e Geoestatística de solos: uma discussão em 10 anos. São Paulo: Geociências UNESP, 38(4), 1097-1104. https://doi.org/10.5016/geociencias.v38i4.14112

Santos, R. L., Andrade, H. O. (2008). Avaliação quantitativa do conforto térmico de uma cidade em área de transição climática: Feira de Santana-Bahia, Brasil. Revista de Geografía Norte Grande, 40, 77-84. http://dx.doi.org/10.4067/S0718-34022008000200005

Santo, S. M., Silva, B. C. M. N., Santos, R. L., Fernandes, R. B. (2013). População e meio ambiente no umbral do século XXI na cidade de Feira de Santana (Bahia-Brasil). Barcelona: Rev. Elet. de Geografia y ciencias sociales.17, 425. http://www.ub.edu/geocrit/sn/sn-425.htm

Silva, A. B. (2018). Análise quantitativa espacial: conceitos e fundamentos. Curitiba: Appris, 1.

Silva, S. A., Lima, J. S. S. (2009). Lógica Fuzzy no mapeamento de variáveis indicadoras de fertilidade do solo. Chile: IDESIA, 27(3), 41-46. http://dx.doi.org/10.4067/S0718$\underline{34292009000300007}$

Subbarao, G. V., Ito, O., Berry, W. L., Wheele R. (2003). Sodium-A Functional Plant Nutrient. Critical Reviews in Plant Sciences, 22(5), 391-416. https://doi.org/10.1080/07352680390243495

Souza, H. A., Cavalcante, A. C. R., Tonucci, R. G., Pompeu, R. C. F. F., Souza, M. C. M. R. (2015). Diagnóstico da fertilidade do solo em áreas de sequeiro de agricultores familiares em municipios do sertão dos Inhamuns. SOBRAL: Embrapa. 
Modelagem geoestatística de elementos maiores dos solos de Feira de Santana-Ba, Brasil Mudanças ambientais e riscos

Zonta, J. H., Brandão, Z. N., Medeiros, J. C., Sana, R. S., Sofiatti, V. (2014). Variabilidade espacial da fertilidade do solo em área cultivada com algododeiro no cerrado do Brasil. Campina Grande: Rev. Bras. Eng. Agrícola.18(6), 509-602. https://doi.org/10.1590/S1415$\underline{43662014000600005}$

Artigo recebido em/ Received on: 01/04/2020

Artigo aceite para publicação em/ Accepted for publication on: 13/05/2020 